\title{
Isolation and Identification of Fusarium solani f. sp. glycines from Soil on Modified Nash and Snyder's Medium
}

\author{
J. H. Cho, Department of Plant Resources, Dongguk University, Seoul, Korea; J. C. Rupe and M. S. Cummings, \\ Department of Plant Pathology, University of Arkansas, Fayetteville; and E. E. Gbur, Jr., Agricultural Statistics \\ Laboratory, University of Arkansas, Fayetteville
}

\begin{abstract}
Cho, J. H., Rupe, J. C., Cummings, M. S., and Gbur, E. E., Jr. 2001. Isolation and identification of Fusarium solani f. sp. glycines from soil on modified Nash and Snyder's medium. Plant Dis. 85:256-260.

Modified Nash and Snyder's medium (MNSM) has been used to study soil populations of the fungus Fusarium solani f. sp. glycines, the causal agent of sudden death syndrome (SDS) of soybean. However, no studies have been conducted to confirm the accuracy of this technique in enumerating the SDS pathogen. To determine what portion of the colonies enumerated on MNSM are the SDS pathogen, 282 isolates resembling $F$. solani f. sp. glycines were collected from soil of two fields with a history of SDS in Arkansas using a soil dilution method with MNSM. The colony morphology of these isolates was compared on MNSM and on potato dextrose agar (PDA). Of these isolates, 112 were tested for pathogenicity on soybean in the greenhouse. In addition to fungi that produced colonies typical of $F$. solani f. sp. glycines on MNSM, 5 isolates each of four common colony types on MNSM were collected from each field for a total of 40 isolates. These isolates were compared to F. solani f. sp. glycines for colony morphology on PDA and for pathogenicity. Isolates that had colonies on MNSM that resembled $F$. solani f. sp. glycines had colony morphologies on PDA similar to this pathogen and produced SDS-like foliar symptoms in greenhouse inoculations of soybean. There was a significant quadratic relationship between foliar symptom severity and plant fresh weight. None of the other isolates tested resembled $F$. solani f. sp. glycines on either MNSM or PDA or produced SDSfoliar symptoms in greenhouse inoculations. These non-SDS isolates were F. solani, F. merismoides, a Pythium sp., and a Paecilomyces sp. All of these isolates produced some root rot, but significantly less than the $F$. solani f. sp. glycines reference isolate. The results of this study established that soil populations of $F$. solani f. sp. glycines can be accurately enumerated using MNSM. It should be noted that, on both MNSM and PDA, F. solani f. sp. glycines can resemble some isolates of $F$. solani $\mathrm{f}$. sp. phaseoli, so pathogenicity tests of random isolates may be required to confirm the forma specialis especially in fields that have a history of both Glycines max and Phaseolus vulgaris.
\end{abstract}

Sudden death syndrome (SDS), caused by the fungus Fusarium solani f. sp. glycines, is an important soilborne disease of soybean (21). Occurring in most of the soybean-growing areas of the United States and Canada and in many parts of Brazil and Argentina, this disease attacks vigorously growing soybean during reproductive development. Although caused by a soilborne pathogen, SDS produces distinctive foliar symptoms that begin as interveinal chlorotic spots, progress into interveinal chlorotic and necrotic streaks, and eventu-

Corresponding author: J. C. Rupe

E-mail: jrupe@comp.uark.edu

Published with the approval of the Director, Arkansas Agricultural Experiment Station, manuscript \# 00035 .

This research was funded in part by a grant from the Arkansas Soybean Promotion Board.

Accepted for publication 1 November 2000.

Publication no. D-2001-0110-01R

(c) 2001 The American Phytopathological Society ally result in defoliation, with the petioles remaining attached to the stem. Yield losses vary depending on distribution of the disease in the field and severity of the disease in the affected areas, but in severely affected areas, can approach $100 \%$ (J. C. Rupe, unpublished data).

As with other soilborne diseases, determining the density of the pathogen in the soil and distribution in the plant can be very useful in understanding the ecology of the pathogen and the epidemiology of the disease. With many soilborne pathogens, such studies are conducted using selective media. On a selective medium for $F$. solani f. sp. phaseoli developed by S. M. Nash and W. C. Snyder (30), the fungus produces a colony distinctive from any other soil fungi growing on the medium (16). These colonies have been considered to represent only $F$. solani f. sp. phaseoli, although no data have been published supporting this assertion $(6,8,10,11,15)$. On this medium, $F$. solani f. sp. glycines produces a colony that is very similar to $F$. solani f. sp. phaseoli (J. C. Rupe, unpublished data).
Although it appears that Nash and Snyder's medium is very useful in enumerating F. solani f. sp. phaseoli, other media used with other pathogens are not as effective at identifying host-specific pathogens within a species. For example, Komoda's medium is the primary medium used in enumerating $F$. oxysporum (13). Even though colonies of $F$. oxysporum can be enumerated effectively on this medium, only a portion of the colonies enumerated represent the pathogen being studied, while the other colonies represent nonpathogenic strains of the fungus $(2,4,5,7,9,19,27)$. As a result, studies of soil populations of pathogenic strains of $F$. oxysporum require extensive pathogenicity testing to determine what proportion of each sample represents the pathogen.

F. solani f. sp. glycines produces a distinctive colony on Nash and Snyder's medium. Using a dilution plating technique and a modified Nash and Snyder's medium (MNSM), soil densities of $F$. solani isolates with this colony type have been determined in soils from fields with SDS in relationship to soil depth (24), soil chloride concentration (26), or crop rotation (25). This technique has also been used to relate densities of $F$. solani f. sp. glycines in soil to severity of SDS (29) and densities in the plant to cultivar resistance (14). In these last two studies, pathogenicity tests were performed on a few isolates, all of which were reported to be pathogenic, but no detailed results were published.

The objectives of our study were to (i) determine what proportion of the colonies enumerated on MNSM from soil collected from fields with SDS were $F$. solani $\mathrm{f}$. sp. glycines and (ii) determine if other fungi growing on MNSM also caused SDS-like symptoms.

\section{MATERIALS AND METHODS}

Soil was collected from nine plots in each of two fields with a history of SDS. The fields were located at the Pine Tree Station, Colt, AR, and the Cotton Branch Station, Marianna, AR. The soils were a Crowley silt loam and a Loring silt loam, respectively. Each plot was planted with soybean cv. Hartz 6686 in four rows, $6 \mathrm{~m}$ long, and rows were spaced $0.91 \mathrm{~m}$ apart. Plots were randomly selected from a test area of $840 \mathrm{~m}^{2}$. Soil samples (composed of six bulked samples totaling approximately $500 \mathrm{~cm}^{3}$ ) were collected on 27 July 1997 
from the center two rows of each plot to a depth of $15 \mathrm{~cm}$ using a 2.5 -cm-diameter soil probe.

To assay the soil, each sample was thoroughly mixed and five 2-g subsamples removed. Each subsample was transferred to $100 \mathrm{ml}$ of deionized water in a $250-\mathrm{ml}$ Erlenmyer flask. The flasks were agitated on a wrist-action shaker for $30 \mathrm{~min}$ and 10and 20-fold dilutions were made from the original suspension. From each of the dilutions, a 1-ml aliquot was spread over the surface of MNSM in 9-cm-diameter plastic petri dishes. There were five plates per dilution, and all plates were incubated at room temperature and light for seven days. MNSM medium consisted of $20 \mathrm{~g}$ of agar, $15 \mathrm{~g}$ of peptone, $1 \mathrm{~g}$ of $\mathrm{KH}_{2} \mathrm{PO}_{4}, 0.5 \mathrm{~g}$ of $\mathrm{MgSO}_{4} \cdot 7 \mathrm{H}_{2} \mathrm{O}$, and 1 liter of water (25). After autoclaving the medium for $20 \mathrm{~min}$ and cooling to $45^{\circ} \mathrm{C}, 1 \mathrm{~g}$ of streptomycin, $2.4 \mathrm{~g}$ of pentachloronitrobenze (PCNB, $75 \% \mathrm{WP}$ ), $1 \mathrm{~g}$ of chlortetracycline, and 0.5 $\mathrm{g}$ of rifampicin were added and thoroughly mixed.

After 7 days, isolations were made from 282 fungal colonies that resembled $F$. solani f. sp. glycines on MNSM by transferring the fungi to potato dextrose agar (PDA; Difco Laboratories, Detroit, MI). This colony type on MNSM, identical to those described for $F$. solani $\mathrm{f}$. sp. phaseoli (16), was small, lacked aerial mycelium, and exhibited an irregular margin, a raised center, and a chalky appearance. After 7 days on PDA at room temperature and ambient light, the color and morphology of each isolate was recorded.

From these 282 isolates, 57 were randomly selected from the Pine Tree Station and 55 from the Cotton Branch Station for pathogenicity tests in the greenhouse. Inoculum of each isolate was prepared by growing the isolate on PDA for 5 days at room temperature under florescent lights (10 h/day). Three 1-cm-diameter plugs were cut from the growing edge of the culture and aseptically transferred to sterilized sorghum seed. For each isolate, 125 $\mathrm{g}$ of sorghum seed was placed in a 500-ml Erlenmyer flask with $150 \mathrm{ml}$ of deionized water. The seeds were autoclaved for 50 min on two consecutive days and inoculated. Inoculum was incubated for 15 days and shaken once daily to insure complete colonization of the seed.

Pathogenicity and aggressiveness of each isolate were determined in the greenhouse. Plastic flats ( 30 by 60 by $6 \mathrm{~cm}$ ) were filled with a steam pasteurized soil mix consisting of 10 parts soil, 4 parts potting mix, 2 parts vermiculite, and 1 part sand (vol:vol). Six equally spaced furrows were formed across the width of the flat to a depth of $5 \mathrm{~cm}$ and $20 \mathrm{ml}$ of inoculum was spread evenly along the bottom of each furrow. The inoculum was covered with 2 $\mathrm{cm}$ of soil mix and 10 seeds of the SDSsusceptible soybean cv. Hartz 6686 were placed in the furrow. The seeds were cov- ered with more soil mix, placed in the greenhouse at $25 \pm 2{ }^{\circ} \mathrm{C}$, and watered as needed. After 4 weeks, each plant in each row was rated for percent leaf area with symptoms of SDS using the Horsfall-Barrett scale, where $0=0 \%, 1=1$ to $3 \%, 2=$ 4 to $6 \%, 3=7$ to $12 \%, 4=13$ to $25 \%, 5=$ 26 to $50 \%, 6=51$ to $75 \%, 7=76$ to $88 \%$, $8=89$ to $94 \%, 9=95$ to $97 \%, 10=98$ to $99 \%$, and $11=100 \%$ (18). Ratings were converted to the midpoint percentage of each range and averaged across the row before analysis. Tests were conducted in a randomized complete block design with three replications. Each row represented a plot of one isolate. All isolates were tested twice. Because of the large number of isolates, each test was divided into four groups of isolates that were tested separately. To be able to compare isolates across groups, a standard $F$. solani $\mathrm{f}$. sp. glycines isolate (isolate 171) was included with the test. This isolate was isolated from the roots of a soybean plant with SDS symptoms at the Cotton Branch Station, Marianna, AR, in 1991 and consistently produced severe SDS symptoms in greenhouse inoculations (J. C. Rupe, unpublished data). To standardize results across tests, the severity of each test isolate was divided by the severity on the standard isolate. The resulting proportions were then analyzed using analysis of variance (ANOVA) with location and isolate as fixed effects and test as a random effect. Means were compared using the Fisher's protected least significant difference (LSD) procedure. The analysis was conducted

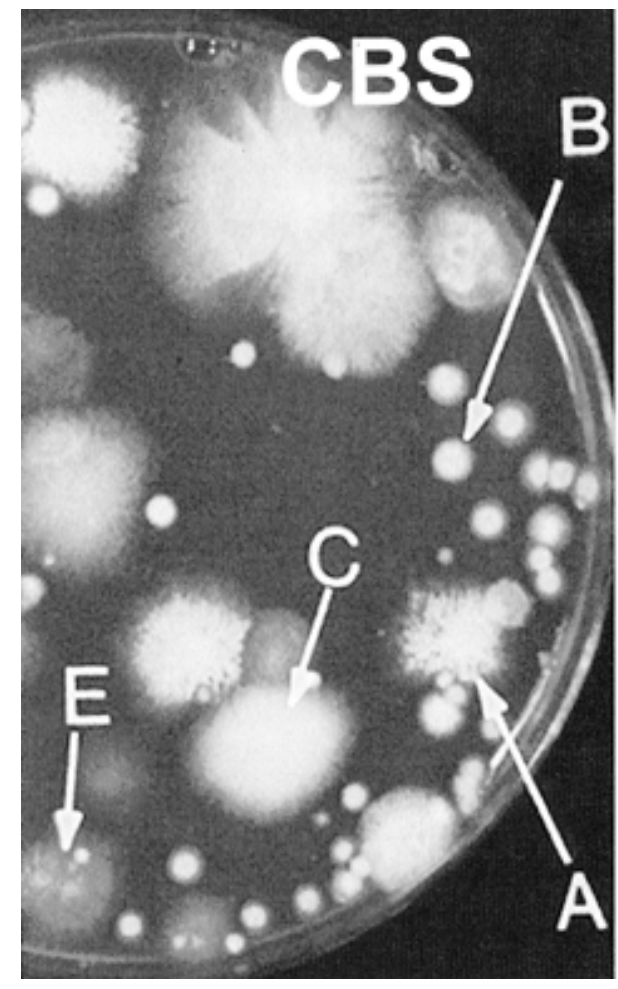

Fig. 1. Colonies of A, Fusarium solani f. sp. glycines, B, Paecilomyces sp., C, F. solani, D, Pythium sp., and E, F. merismodes on modified Nash and Snyder's medium from soils collected at the Cotton Branch Station (CBS), Marianna, AR, and the Pine Tree Station (PTS), Colt, AR.

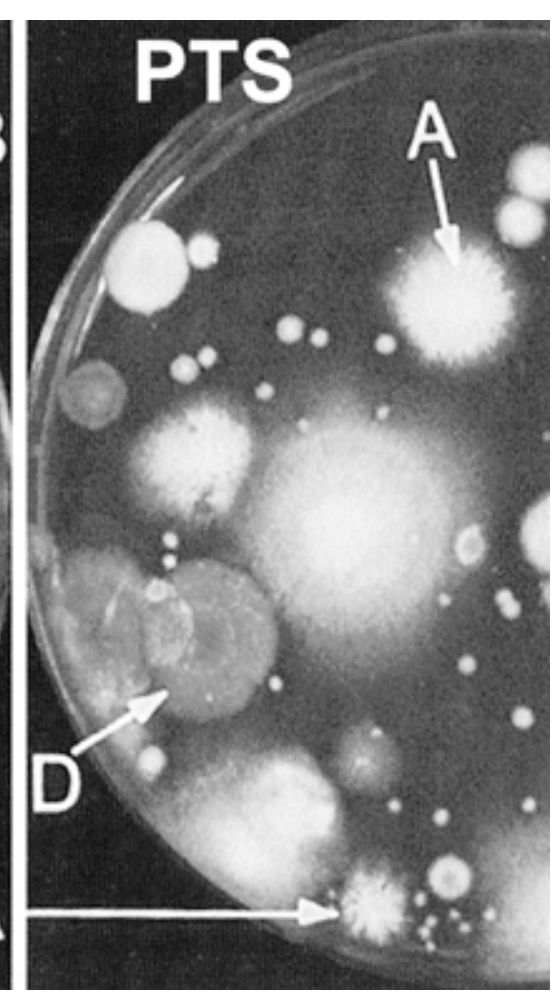

using PROC GLM in SAS (version 7; SAS Institute, Cary, NC).

At the end of each test, all plants within a replication were cut off at the soil line and the total fresh top weight determined. As with the disease ratings, the proportion was calculated by dividing the weight of the plants inoculated with the test isolates by the weight of the plants inoculated with the standard isolate of $F$. solani f. sp. glycines (isolate 171) in each group of each test. These proportions were analyzed using the same procedures as described for the foliar symptoms.

The relationship of plant weight to foliar symptoms severity was determined by regressing the mean plant weight ratio with the mean SDS severity ratio using weighted least squares. Statistical analyses were carried out using PROC REG in SAS (version 7; SAS Institute).

To determine the pathogenicity on soybean of the other microorganisms present in soil assays, single-spore isolates of four common colony types that differed from $F$. solani f. sp. glycines on MNSM were collected from four plots in the same fields at Pine Tree Station and Cotton Branch Station on 17 June 1999. The soil was assayed as previously described. The colony types were designated B, C, D, and E (Fig. 1). Five isolates of each colony type were collected from each location for a total of 40 isolates. Colony morphologies on MNSM and PDA were determined with these isolates as described. Pathogenicity tests were conducted as described previously except that all isolates were tested at

Plant Disease / March 2001 
one time and both the $F$. solani f. sp. glycines isolate 171 and an uninoculated treatment were included as checks. In addition to rating foliar symptoms, the plants were extracted carefully from the soil, the roots washed in running tap water for 30 min, and root rot severity assessed on each plant using a 0 -to-4 scale, in which $0=$ $0 \%, 1=1$ to $25 \%, 2=26$ to $50 \%, 3=51$ to $75 \%$, and $4=76$ to $100 \%$ of the root discolored (12). Each rating was converted to the midpoint of the range of percentages it represented and these percentages for all plants in a replication were averaged before analysis. The roots were separated from the tops of the plants at the soil line and roots and tops were dried at $50^{\circ} \mathrm{C}$ for 1 week and then weighed. The data were analyzed using ANOVA, with location and isolate type as fixed effects and test as a random effect. Means were separated using Fisher's protected LSD. The analysis was conducted using PROC GLM in SAS (version 7; SAS Institute). For simplicity, the data were analyzed by colony type across isolates within each colony type.

Representative isolates of two colony types were sent to the Fusarium Laboratory at the Pennsylvania State University for species identification. Other isolates were grown on PDA, or water agar (3), corn meal agar (Difco Laboratories), or sterile grass leaves for identification.

\section{RESULTS}

All of the 282 isolates that resembled $F$. solani f. sp. glycines on MNSM produced similar colonies on PDA. These were

Table 1. Analysis of variance of foliar symptom severity (\%) or fresh plant weight (g) of soybean inoculated with isolates of Fusarium solani f. sp. glycines collected from soil dilutions of soil collected at two locations in Arkansas using modified Nash and Snyder's medium ${ }^{z}$

\begin{tabular}{lccc}
\hline & \multicolumn{3}{c}{$\boldsymbol{P}$ values } \\
\cline { 2 - 4 } Source & Degrees of freedom & Foliar severity & Top weight \\
\hline Test & 1 & 0.3288 & 0.0002 \\
Rep (test) & 4 & $\ldots$ & $\ldots$ \\
Location & 1 & 0.0519 & 0.2573 \\
Test $\times$ location & 1 & $\ldots$ & $\ldots$ \\
Isolate (location) & 110 & 0.0001 & 0.0001 \\
Test $\times$ isolate (location) & 93 & $\ldots$ & $\ldots$ \\
Mean square error & 419 & $\ldots$ & $\ldots$ \\
\hline
\end{tabular}

${ }^{\mathrm{z}}$ Due to the large number of isolates tested, each test was conducted in four groups of isolates. To standardize the results between groups, all results were expressed as a ratio of either the foliar disease ratings or plant weight of a standard $F$. solani f. sp. glycines isolate, isolate 171. Soil was collected at the Pine Tree Station, Colt, AR, and the Cotton Branch Station, Marianna, AR; $\ldots=$ not applicable.

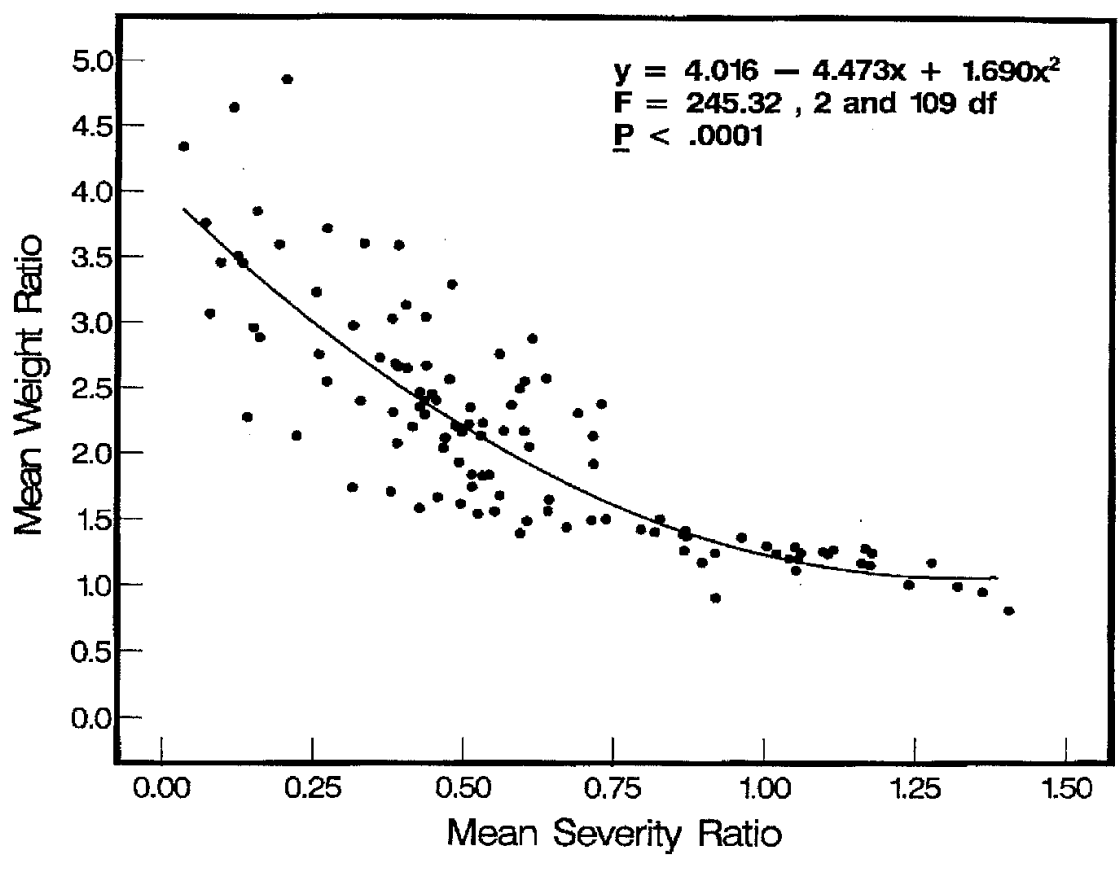

Fig. 2. Relationship of foliar symptoms of sudden death syndrome (SDS) and plant weight in soybean (cv. Hartz 6686) inoculated in the greenhouse with isolates of Fusarium solani f. sp. glycines collected from the soil. There were significant differences between repeated experiments; therefore, data were converted to proportion of either percent foliar symptoms or plant weights of plants inoculated with a standard isolate of $F$. solani f. sp. glycines, isolate 171, originally isolated from a soybean with SDS.

slow-growing, appressed with a blue center and white margin, producing abundant macroconidia but no microconidia. All 112 isolates tested for pathogenicity produced SDS foliar symptoms on soybean in both experiments. There were significant $(P<$ $0.05)$ differences between isolates in foliar symptom severity and plant fresh weight (Table 1). In all, 3 isolates caused more and 77 caused less severe foliar symptoms than the standard isolate, 171, of $F$. solani f. sp. glycines (Table 2). Proportions of foliar symptom severity were significantly $>1$ if larger than 1.294 or $<1$ if less than 0.706 . The foliar symptom severity proportions ranged from 0.03 to 1.41 of isolate 171. The three isolates that induced more severe SDS foliar symptoms than the standard isolate were isolates 703-1-3-1 and 703-1-4-2 (from the Pine Tree Station) and 14-3-1-1 (from the Cotton Branch Station), with proportions of $1.41,1.36$, and 1.32 , respectively. Seventy-seven isolates caused less severe SDS than the standard isolate, with proportions ranging from 0.69 to 0.03 . Of these isolates, 44 originated from the Pine Tree Station and 33 from the Cotton Branch Station.

Plant weight proportions ranged from 0.82 to 4.85 . There was a significant test effect, with mean plant weight ratios in test 1 of 1.61 and in test 2 of 2.61. Inoculation with 61 isolates resulted in plant weights greater than (proportions greater than 2.02) those induced by the standard isolate, with proportions ranging from 2.04 to 4.85 . Of these isolates, 34 originated from the Pine Tree Station and 26 from the Cotton Branch Station.

There was a significant quadratic relationship $(F=245.32$ with 2 and 109 de-

Table 2. Comparison of isolates of Fusarium solani f. sp. glycines recovered on modified Nash and Snyder's medium from soil sampled from two fields in Arkansas with the standard isolate 171 of $F$. solani f. sp. glycines, in the ability to cause foliar symptoms of sudden death syndrome and affect above ground fresh plant weights of soybean cv. Hartz $6686^{y}$

\begin{tabular}{lcc}
\hline & \multicolumn{2}{c}{ Number of isolates } \\
\cline { 2 - 3 } Comparison $^{\mathbf{z}}$ & $\begin{array}{c}\text { Foliar } \\
\text { symptoms }\end{array}$ & $\begin{array}{c}\text { Top plant } \\
\text { fresh weight }\end{array}$ \\
\hline Less & 77 & 0 \\
Equal & 32 & 52 \\
Greater & 3 & 61 \\
\hline
\end{tabular}

${ }^{y}$ Isolate 171 was collected from a soybean plant with sudden death syndrome symptoms at the Cotton Branch Station in 1991.

${ }^{\mathrm{z}}$ Comparison to standard isolate, combined over two experiments, each with three replications. Each experiment consisted of four groups of isolates tested separately; therefore, foliar symptom severities and plant weights were converted to a proportion of the standard F. solani f. sp. glycines isolate, 171. Proportions of foliar symptoms were significantly different from 1 if $<0.706$ or $>1.294$. Proportions of plant weights were significantly different than 1 if $>2.021$. No plant weight proportions were significantly smaller than 1 . 
grees of freedom, $P<0.0001)$ between the proportions of plant weight and foliar symptoms of SDS (Fig. 2). Preliminary analysis indicated that variability of mean dry weight ratios significantly $<1$ were approximately 16 times larger than the corresponding variability for mean severity ratios $\geq 1$.

The other four commonly recovered colony types on MNSM (Fig. 1) had distinctive and consistent colony morphologies on PDA. Colonies of a Paecilomyces sp. (isolate B) were small, white, and compact on MNSM and slow growing with white margins and a pink center on PDA. F. solani (isolate C) produced relatively large white spreading colonies on MNSM and a fast-growing white colony on PDA. Pythium sp. (isolate D) colonies were thin, tan, and relatively large on MNSM and large and white with abundant aerial mycelium on PDA. F. merisoides (isolate E) colonies were thin, tan, and moderate in size on MNSM and small and yellowish on PDA.

None of these species caused foliar symptoms of SDS on soybean in greenhouse inoculations, but did cause some root rot. There were significant species effects for root rot and root dry weight and a significant location-species interaction for top dry weight (Table 3). Averaged across both experiments, plants inoculated with isolate 171 had foliar symptom severity of $67 \%$, root rot severity of $86.5 \%$, root dry weight of $0.03 \mathrm{~g}$, and top dry weight of $0.19 \mathrm{~g}$ (Table 4). Of the species that did not cause SDS, the Pythium sp. caused the highest level of root rot $(44.83 \%)$, whereas the Paecilomyces sp. caused the lowest $(9.89 \%)$. These levels of root rot were significantly less than that caused by isolate 171 , but significantly greater than in the uninoculated control. Plants inoculated with isolates of $F$. solani, $F$. merisoides, a Paecilomyces sp., and a Pythium sp. had significantly greater root weights and, except for the Pythium sp. from the Cotton Branch Station, had significantly greater plant weights than the uninoculated control.

\section{DISCUSSION}

All isolates initially identified as $F$. solani f. sp. glycines based on colony appearance on soil dilution plates of MNSM were the SDS pathogen. These isolates produced very similar colonies on MNSM and PDA. $F$. solani f. sp. phaseoli, a fungus that closely resembles $F$. solani $\mathrm{f}$. sp. glycines in culture and in molecular analysis $(1,17,23)$, has been reported to produce a uniform colony type on Nash and Snyder's medium $(6,8,10,11,15)$, but can vary widely on PDA (28).

All of the fungi identified as $F$. solani $\mathrm{f}$. sp. glycines on MNSM produced SDS-like foliar symptoms in all greenhouse inoculation tests. These isolates differed in aggressiveness, with most isolates being either as aggressive or less aggressive than check isolate 171. Similar variability in aggressiveness between isolates of $F$. solani f. sp. glycines recovered from soybean plants with SDS has been reported (22). This similarity in the range of aggressiveness between isolates of $F$. solani f. sp. glycines originating from either diseased plants or soil implies that the isolates enumerated in the soil assay represent the isolates that could cause SDS.

There was a significant quadratic relationship between severity of foliar symptoms and plant weight. Although other studies reported that greenhouse inoculations with $F$. solani f. sp. glycines resulted in reductions in plant height $(20,22)$, root size (22), and root and shoot weights (20), this is the first report of the effect of a range in foliar symptom severity on plant weight. Of particular interest is the change in variability in plant weight ratio at foliar symptom severity ratios equal to or greater than those caused by isolate 171 (i.e., se- verity ratios $\geq 1$ ). At foliar symptom severity ratios $<1$, there was relatively high variability in the plant weight ratios, implying that foliar symptom severity was only one of a number of factors that contributed to plant weight. It is not known what other factors contributed to plant weight when disease levels were low, but at severity ratios $>1$, the main factor affecting plant growth appears to have been disease. It should be noted that foliar symptom severity ratios of $<0.706$ were significantly lower than 1 . Similar changes in variability in seed yield with changes in disease severity have been observed in the field (J. C. Rupe, unpublished results).

Examination of other common colony types on the soil dilution plates revealed a number of other fungi, including $F$. solani. None of these isolates had colonies on MNSM or PDA that resembled $F$. solani f. sp. glycines and none produced SDS-like foliar symptoms in greenhouse inocula-

Table 3. Analysis of variance of root rot (\%), root dry weight (g), and top dry weight (g) of soybean inoculated with fungal isolates with colony types other than that of Fusarium solani f. sp. glycines collected by soil dilutions on modified Nash and Snyder's medium from soil collected at two locations in Arkansas ${ }^{\mathrm{Z}}$

\begin{tabular}{lrccc}
\hline & & \multicolumn{3}{c}{$\boldsymbol{P}$ values } \\
\cline { 4 - 5 } Source & df & Root rot & Root weight & Plant weight \\
\hline Test & 1 & 0.0077 & 0.5886 & 0.0001 \\
Rep (test) & 4 & $\ldots$ & $\ldots$ & $\ldots$ \\
Location & 1 & 0.8004 & 0.0203 & 0.1405 \\
Test $\times$ location & 1 & $\ldots$ & $\ldots$ & $\ldots$ \\
Colony & 3 & 0.0035 & 0.0281 & 0.0421 \\
Test $\times$ colony & 3 & $\ldots$ & $\ldots$ & $\ldots$ \\
Location $\times$ colony & 3 & 0.3933 & 0.6341 & 0.0041 \\
Test $\times$ location $\times$ colony & 3 & $\ldots$ & $\ldots$ & $\ldots$ \\
Mean square error & 212 & $\ldots$ & $\ldots$ & $\ldots$ \\
\hline
\end{tabular}

${ }^{\mathrm{z}}$ Soil was collected at the Pine Tree Station, Colt, AR, and the Cotton Branch Station, Marianna, $\mathrm{AR} ; \mathrm{df}=$ degrees of freedom; $\ldots=$ not applicable.

Table 4. Root rot severity, root dry weight, and aboveground plant dry weights of soybean cv. Hartz 6686 inoculated in the greenhouse with isolates of four colony types commonly recovered from soil collected at two locations in Arkansas on modified Nash and Snyder's medium and isolate 171 of Fusarium solani $\mathrm{f}$. sp. glycines collected from a soybean with sudden death syndrome ${ }^{\mathrm{x}}$

\begin{tabular}{lcccc}
\hline & & & \multicolumn{2}{c}{ Top dry weight $(\mathbf{g})^{\mathbf{y}}$} \\
\cline { 4 - 5 } Microorganism & ${\text { Root } \operatorname{rot}(\boldsymbol{\%})^{\mathbf{z}}}$ & Root dry weight $(\mathbf{g})$ & CBS & PTS \\
\hline F. solani f. sp. glycines & $86.5 \mathrm{a}$ & $0.03 \mathrm{e}$ & 0.19 & $\ldots$ \\
Pythium spp. & $44.8 \mathrm{~b}$ & $0.10 \mathrm{c}$ & 0.46 & 0.51 \\
F. solani & $19.9 \mathrm{c}$ & $0.11 \mathrm{~b}$ & 0.52 & 0.53 \\
F. merisoides & $17.6 \mathrm{~cd}$ & $0.12 \mathrm{a}$ & 0.55 & 0.60 \\
Paecilomyces spp. & $9.9 \mathrm{~d}$ & $0.10 \mathrm{c}$ & 0.53 & 0.55 \\
Untreated & NA & $0.08 \mathrm{~d}$ & 0.45 & $\ldots$ \\
\hline
\end{tabular}

${ }^{x}$ Numbers followed by the same letter are not significantly different at the $P=0.05$ level by the least significant difference test; NA = not used in the analysis because all of the roots of the control plants had discoloration percentages of 0 and no variability between replications; $\ldots=$ does not apply. Least significant differences (LSD) at $P=0.05$ for top dry weights resulting from inoculation with isolates from Cotton Branch Station (CBS) or Pine Tree Station (PTS) between isolate 171 and the untreated check, or across all treatments. Three LSDs were necessary because of uneven sample size between colony type (sample size $=16$ ) and 171 or untreated (sample size $=4$ ). LSD between CBS and PTS isolates $=0.02$, LSD between 171 and untreated $=0.04$, and LSD between isolates and 171 and untreated $=0.03$

y Plant dry weights determined after drying the plant material at $50^{\circ} \mathrm{C}$ for 1 week.

${ }^{\mathrm{z}}$ Root rot ratings determined on a 1 -to- 4 scale where $0=$ no root rot, $1=1$ to $25 \%, 2=26$ to $50 \%, 3$ $=51$ to $75 \%$, and $4=75$ to $100 \%$ root rot (12). Ratings were converted to the midpoint percentage of each range before analysis. F. solani f. sp. glycines isolate 171 collected in 1991 from a soybean with sudden death syndrome at the Cotton Branch Station (CBS), Marianna, AR, was used as a comparison. 
tions. Although all of these non-SDS isolates produced some level of root rot, they all stimulated root growth and all but the Pythium sp. from Cotton Branch Station stimulated top weight. It is not clear if this stimulation in plant growth by these nonSDS isolates was an effect of the fungi or a nutritional effect of the sorghum seed inoculum.

The results presented in this article establish that $F$. solani f. sp. glycines produces a single, identifiable colony type in soil dilutions on MNSM. This makes soil dilution plating on MNSM a very powerful tool for studying soil populations of $F$. solani f. sp. glycines. However, one potential source of error in this procedure is the morphological similarity of $F$. solani f. sp. glycines and $F$. solani f. sp. phaseoli. Although isolates of $F$. solani $\mathrm{f}$. sp. phaseoli do not cause SDS-like foliar symptoms on soybean and, while similar, are distinct at the molecular level $(1,17,23)$, they can have colony morphologies similar to those of the soybean pathogen on both MNSM and PDA (16,20,22). Therefore, periodic pathogenicity testing of isolates from soil dilution plating should be made when studying $F$. solani $\mathrm{f}$. sp. glycines to ensure that the colonies being counted represent only the SDS pathogen, especially in fields with a history of both Phaseolus vulgaris and Glycines max production.

\section{ACKNOWLEDGMENTS}

We thank C. M. Becton and J. Velie for technical assistance, J. Juba for the identification of the Fusarium isolates, and C. Rothrock for the identification of the Pythium sp.

\section{LITERATURE CITED}

1. Achenbach, L. A., Patrick, J., and Gray, L. 1996. Use of RAPD markers as a diagnostic tool for the identification of Fusarium solani isolates that cause soybean sudden death syndrome. Plant Dis. 80:1228-1232.

2. Baker, R., and Nash, S. M. 1965. Ecology of plant pathogens in soil. VI. Inoculum density of Fusarium solani f. sp. phaseoli in bean rhizosphere as affected by cellulose and supplemental nitrogen. Phytopathology 55:13811382.

3. Barnett, H. L., and Hunter, B. B. 1998. Illustrated Genera of Imperfect Fungi, 4th ed. American Phytopathological Society Press, St. Paul, MN.

4. Ben-Yephet, Y., Reuven, M., and Genizi, A. 1994. Effects of inoculum depth and density on Fusarium wilt of carnations. Phytopathol- ogy 84:1393-1398.

5. Ben-Yephet, Y., Reuven, M., Szmulewich, Y., and Mor, Y. 1994. Effect of methyl bromide on the control of Fusarium oxysporum f. sp. dianthi propagules in carnation greenhouse soil and on inoculum increase after one growth cycle of carnation. Crop Prot. 13:357361.

6. Burke, D. W., Holmes, L. D., and Barker, A. W. 1972. Distribution of Fusarium solani f. sp. phaseoli and bean roots in relation to tillage and soil compaction. Phytopathology 62:550-554.

7. DeVay, J. E., Gutierrez, A. P., Pullman, G. S., Wakeman, R. J., Garber, R. H., Jeffers, D. P., Smith, S. N., Goodell, P. B., and Roberts, P. A. 1997. Inoculum densities of Fusarium oxysporum f. sp. vasinfectum and Meloidogyne incognita in relation to the development of Fusarium wilt and the phenology of cotton plants (Gossypium hirsutum). Phytopathology 87:341-346.

8. Dryden, P, and Van Alfen, N. K. 1984. Soil moisture, root system density, and infection of roots of pinto beans by Fusarium solani $\mathrm{f}$. sp. phaseoli under dryland conditions. Phytopathology 74:132-135.

9. Elmer, W. H., and Lacy, M. L. 1987. Effects of crop residues and colonization of plant tissues on propagule survival and soil populations of Fusarium oxysporum f. sp. apii race 2. Phytopathology 77:381-387.

10. Hall, R. 1981. Correction: Benomyl increases the selectivity of the Nash-Snyder medium for Fusarium solani f. sp. phaseoli. Can. J. Plant Pathol. 3:97-102.

11. Hall, R., and Phillips, L. G. 1992. Effects of crop sequence and rainfall on population dynamics of Fusarium solani f. sp. phaseoli in soil. Can. J. Bot. 70:2005-2008.

12. Hwang, S. F., Howard, R. J., Chang, K. F., Park, B., and Burnett, P. A. 1994. Etiology and severity of Fusarium root rot of lentil in Alberta. Can. J. Plant Pathol. 16:295-303.

13. Komada, H. 1975. Development of a selective medium for quantitative isolation of Fusarium oxysporum from natural soil. Rev. Plant Prot. Res. 8:114-125.

14. Luo, Y., Myers, O., Lightfoot, D. A., and Schmidt, M. E. 1999. Root colonization of soybean cultivars in the field by Fusarium solani f. sp. glycines. Plant Dis. 83:11551159.

15. Maloy, O. C., and Burkholder, W. H. 1959. Some effects of crop rotation on the Fusarium root rot of bean. Phytopathology 49:583-587.

16. Nash, S. M., and Alexander, J. V. 1965. Comparative survival of Fusarium solani f. cucurbitae and F. solani f. phaseoli in soil. Phytopathology 55:963-966.

17. Nash, S. M., and Snyder, W. C. 1962. Quantitative estimations by plate counts of propagules of the bean root rot Fusarium in field soils. Phytopathology 52:567-572.

18. O'Donnell, K., and Gray, L. E. 1995. Phylo- genetic relationships of the soybean sudden death syndrome pathogen Fusarium solani f. sp. phaseoli inferred from rDNA sequence data and PCR primers for its identification. MPMI 8:709-716.

19. Redman, C. E, King, E. P., and Brown, J. F., Jr. 1969. Elanco Conversion Tables for Barratt-Horsfall Rating Numbers. Eli Lilly and Co. Research Labs, Indianapolis, IN.

20. Rowe, R. C., Farley, J. D., and Coplin, D. L. 1977. Airborne spore dispersal and recolonization of steamed soil by Fusarium oxysporum in tomato greenhouses. Phytopathology 67:1513-1517.

21. Roy, K. W., Lawrence, G. W., Hodges, H. H., McLean, K. S., and Killebrew, J. F. 1989 Sudden death syndrome of soybean: Fusarium solani as incitant and relation of Heterodera glycines to disease severity. Phytopathology 79:191-197.

22. Roy, K. W., Rupe, J. C., Hershman, D. E., and Abney, S. A. 1997. Sudden death syndrome of soybean. Plant Dis. 81:1100-1111

23. Rupe, J. C. 1989. Frequency and pathogenicity of Fusarium solani recovered from soybeans with sudden death syndrome. Plant Dis. 73:581-584.

24. Rupe, J. C., Correll, J. C., and Yount, P. 1993. Differentiation of the soybean sudden death syndrome pathogen, Fusarium solani, from other isolates of $F$. solani based on cultural morphology and mitochondrial DNA RFLPs. (Abstr.) Phytopathology 83:1423.

25. Rupe, J. C., Robbins, R. T., Becton, C. M. Sabbe, W. A., and Gbur, E. E., Jr. 1999. Vertical and temporal distribution of Fusarium solani and Heterodera glycines on the development of sudden death syndrome of soybean in two Arkansas fields. Soil Biol. Biochem. 31:245-251.

26. Rupe, J. C., Robbins, R. T., and Gbur, E. E., Jr. 1997. Effect of crop rotation on soil densities of Fusarium solani and Heterodera glycines and on development of sudden death syndrome of soybean. Crop Prot. 18:575-580.

27. Rupe, J. C., Widick, J. D., Sabbe, W. E., Robbins, R. T., and Becton, C. B. 2000. Effect of chloride and soybean cultivar on yield and the development of sudden death syndrome, soybean cyst nematode, and southern blight. Plant Dis. 84:669-674.

28. Scherm, H., Yang, X. B., and Lundeen, P. 1998. Soil variables associated with sudden death syndrome in soybean fields in Iowa. Plant Dis. 82:1152-1157.

29. Schneider, R. W. 1984. Effects of nonpathogenic strains of Fusarium oxysporum on celery root infection by $F$. oxysporum f. sp. apii and a novel use of the Lineweaver-Burk double reciprocal plot technique. Phytopathology 74:646-653

30. Snyder, W. C., Nash, S. M., and Trujillo, E. 1959. Multiple clonal types of Fusarium solani phaseoli in field soil. Phytopathology 49:310-312. 